\title{
The hypoxia-induced paralogs Scylla and Charybdis inhibit growth by down-regulating S6K activity upstream of TSC in Drosophila
}

\author{
Jan H. Reiling and Ernst Hafen ${ }^{1}$ \\ Zoologisches Institut, Universität Zürich, CH-8057 Zürich, Switzerland
}

\begin{abstract}
Diverse extrinsic and intrinsic cues must be integrated within a developing organism to ensure appropriate growth at the cellular and organismal level. In Drosophila, the insulin receptor/TOR/S6K signaling network plays a fundamental role in the control of metabolism and cell growth. Here we show that scylla and charybdis, two homologous genes identified as growth suppressors in an EP (enhancer/promoter) overexpression screen, act as negative regulators of growth. The simultaneous loss of both genes generates flies that are more susceptible to reduced oxygen concentrations (hypoxia) and that show mild overgrowth phenotypes. Conversely, scylla or charybdis overactivation reduces growth. Growth inhibition is associated with a reduction in S6K but not PKB/Akt activity. Together, genetic and biochemical analysis places Scylla/Charybdis downstream of PKB and upstream of TSC. Furthermore, we show that scylla and charybdis are induced under hypoxic conditions and that scylla is a target of Drosophila HIF-1 (hypoxia-inducible factor-1) like its mammalian counterpart RTP801/REDD1, thus establishing a potential cross-talk between growth and oxygen sensing.
\end{abstract}

[Keywords: Insulin signaling; S6 kinase; TSC; hypoxia; RTP801; REDD1]

Supplemental material is available at http://www.genesdev.org.

Received May 19, 2004; revised version accepted September 15, 2004.

The control of growth in response to intrinsic and extrinsic factors is important for the development of every organism. Deregulated growth can have devastating consequences such as tumor formation. The evolutionarily conserved Insulin/IGF receptor (Inr)/Target of Rapamycin (TOR) signaling network plays an important role in modulating growth, metabolism, reproduction, and life span in response to intracellular and extracellular signals in species ranging from invertebrates to humans (Garofalo 2002; Jacinto and Hall 2003). In Drosophila, viable mutant combinations of positive components of the Drosophila Inr cascade such as Inr, chico (the homolog of vertebrate IRS1-4), PKB (Protein kinase B, also known as Akt) and PDK1 (3-phosphoinositide-dependent protein kinase-1) lead to developmentally delayed and proportionally reduced small flies, displaying a reduction in cell size and number (Bohni et al. 1999; Brogiolo et al. 2001; Rintelen et al. 2001). On the other hand, loss of PTEN (phosphatase and tensin homolog on chromosome ten), which antagonizes PI3K activity by dephosphory-

${ }^{1}$ Corresponding author.

E-MAIL hafen@zool.unizh.ch; FAX 41-1-635-68-20.

Article published online ahead of print. Article and publication date are at http://www.genesdev.org/cgi/doi/10.1101/gad.322704. lating the 3 '-position of phosphoinositides, leads to hypertrophy and hyperplasia (Goberdhan et al. 1999; Huang et al. 1999; Gao et al. 2000). In humans, loss of the tumor suppressor PTEN is observed frequently in glioblastomas, prostate cancers, and endometrial cancers, and PTEN germline mutations are linked to dominant hamartoma syndromes like Cowden syndrome, LhermitteDuclose disease, Proteus syndrome, and Bannayan-Zonana syndrome (Sulis and Parsons 2003). Genetic studies in Drosophila indicate that PKB has a crucial role in signaling downstream of PTEN since flies completely lacking PTEN function can be rescued to viability by lowering PKB activity (Stocker et al. 2002).

The TOR/S6K (S6 kinase) branch of the growth modulatory network is negatively regulated by the tumor suppressor Tsc1 (hamartin)/Tsc2 (tuberin) complex. Tuberous sclerosis complex (TSC) is an autosomal-dominant disorder characterized by the formation of hamartomas, benign tumors that arise in various tissues (Pan et al. 2004). In Drosophila, cells devoid of Tsc1/Tsc2 function are increased in size (Gao and Pan 2001; Potter et al. 2001; Tapon et al. 2001). Tsc2 and, more weakly, Tsc1 were found to physically associate with dTOR, thereby inhibiting dTOR kinase activity (Gao et al. 2002). Other 
studies reported an inhibitory role of PKB on Tsc1-Tsc2 by PKB-mediated phosphorylation of Tsc2 (Inoki et al. 2002; Manning et al. 2002). Recently, the small GTPase Rheb (Ras homolog enriched in brain) has been identified as a new positive growth effector acting downstream of Tsc1-Tsc2 and upstream of TOR. Mechanistically, Tsc2 acts as GTPase-activating protein (GAP) toward Rheb (Garami et al. 2003; Inoki et al. 2003a; Saucedo et al. 2003; Stocker et al. 2003; Tee et al. 2003; Zhang et al. 2003). The molecular mechanism how Rheb relays the signal to TOR is currently unknown. $d T O R$ mutants show a growth deficit that is more pronounced in endoreplicative tissues than in mitotic tissues /Oldham et al. 2000; Zhang et al. 2000). An effector of mTOR is S6K, which upon activation by mTOR phosphorylates ribosomal protein S6. S6K-mediated S6 phosphorylation has been thought to lead to a preferential translation of mRNAs encoding ribosomal proteins and proteins of the translational apparatus although the significance of this S6K function has been questioned recently (Tang et al. 2001; Stolovich et al. 2002; Pende et al. 2004). Inr/TOR signaling activity culminates in the regulation of translation rate by controlling $\mathrm{S} 6 \mathrm{~K}$ and the translational repressor 4E-BP1 (Gingras et al. 2004). S6K mutant flies are small but in contrast to mutants of the Inr pathway, only cell size is reduced without a change in cell number (Montagne et al. 1999). Therefore, loss of S6K function reduces growth and body size to a lesser extent than loss of other positive components acting further upstream in the cascade.

Growth is modulated by extrinsic factors such as nutrients, temperature, and hypoxia (Palos and Blasko 1979; Frazier et al. 2001; Azevedo et al. 2002). However, their link to the Inr/TOR signaling network are not well defined. Although it is known that starvation results in a reduction in the levels of insulin-like peptides and a reduction in S6K activity in Drosophila (Oldham et al. 2000; Ikeya et al. 2002), little is known about whether temperature or hypoxia regulates the activity of this pathway. It is conceivable that mutations in genes coding for factors mediating the modulation of growth in response to external stimuli have escaped detection because they do not exhibit a very strong phenotype under standard culture conditions. For example, overexpression of the Forkhead transcription factor FOXO3a, the human homolog of Drosophila dFOXO, produces a very subtle small eye phenotype under normal nutrient conditions. Under starvation, however, this phenotype is massively exacerbated, inducing a further eye size reduction and cell death. Furthermore, dFOXO mutant flies are viable and do not show an (over)growth phenotype in an otherwise wild-type background under normal conditions (Junger et al. 2003).

Genes like $d F O X O$ were missed in genetic loss-offunction screens aimed at identifying growth-regulatory genes (1) because they have only mild or missing mutant phenotypes under normal conditions and/or (2) because their function is masked by redundancy.

Genes acting in a redundant manner can be identified in a complementary gain-of-function approach using EP (enhancer/promoter) elements (Rorth 1996). Screening $>4000$ novel EP lines, we found two insertions in the scylla locus as suppressors of a PKB/PDK1-dependent eye overgrowth phenotype. We identified a second gene in the Drosophila genome with homology to scylla named charybdis. Homologs of these genes also exist in mammals, and they have been implicated in the response of a cell to hypoxia or more generally as stressinduced genes having either pro- or anti-apoptotic functions. We present evidence that scylla and charybdis, like some of their mammalian homologs, are induced by hypoxia and that Scylla and Charybdis act as partially redundant negative regulators of growth by controlling S6K but not PKB activity.

\section{Results}

Identification of scylla and charybdis

In order to identify novel genes involved in growth regulation by the Inr/TOR pathway, we performed an EP overexpression screen using a double-headed EP element. We used a genetically sensitized system involving coexpression of PKB and PDK1 (achieved by using EP837 that drives endogenous $P D K 1$ ) in the eye, which leads to a big eye phenotype (Fig. 1B). Pilot experiments demonstrated that overexpression of PTEN or a dominant-negative version of the catalytic subunit of Drosophila PI3K, Dp110, were not able to suppress the PKB/PDK1-dependent phenotype. Thus, our screening system is likely to identify components acting downstream of or in parallel to PKB/PDK1. For example, coexpression of Tsc1/Tsc2 strongly suppresses the phenotype of our tester flies (data not shown).

We identified two EP insertions (EP22.1, hereafter named EPSCy, and EP9.85) in the scylla locus as suppressors of the PKB/PDK1 bulging eye phenotype (Fig. 1C). BLASTP search with the Scylla amino acid sequence revealed another homologous protein encoded in the Drosophila genome termed Charybdis. scylla (scy, CG7590) and charybdis (char, CG7533) are separated by $\sim 232 \mathrm{~kb}$ of genomic DNA. Their gene products share a high degree of homology (38\% identity, 49\% similarity), suggestive of a gene duplication event (Fig. 1F,G). We checked whether charybdis overexpression would behave similarly to scylla in the $P K B / P D K 1$ overexpression assay using EP1035 (hereafter named EPchar). Indeed, the big eye phenotype of the tester system is also suppressed by EPchar (Fig. 1D). UAS transgenes with either the scylla or charybdis cDNA recapitulate the suppression phenotype of the corresponding EP element (data not shown). Coexpression of scylla and charybdis further ameliorates the suppression phenotype to a nearly wild-type situation (Fig. 1E). Notably, scylla or charybdis overexpression on their own using a panel of different eye/wing Gal4 drivers reduced adult organ size. Coexpression of the caspase inhibitors p35 or DIAP1 did not rescue the small eye phenotype induced by expression of either scylla or charybdis in the eye. Moreover, no elevated cell death in eye imaginal disks overexpressing scylla/ 

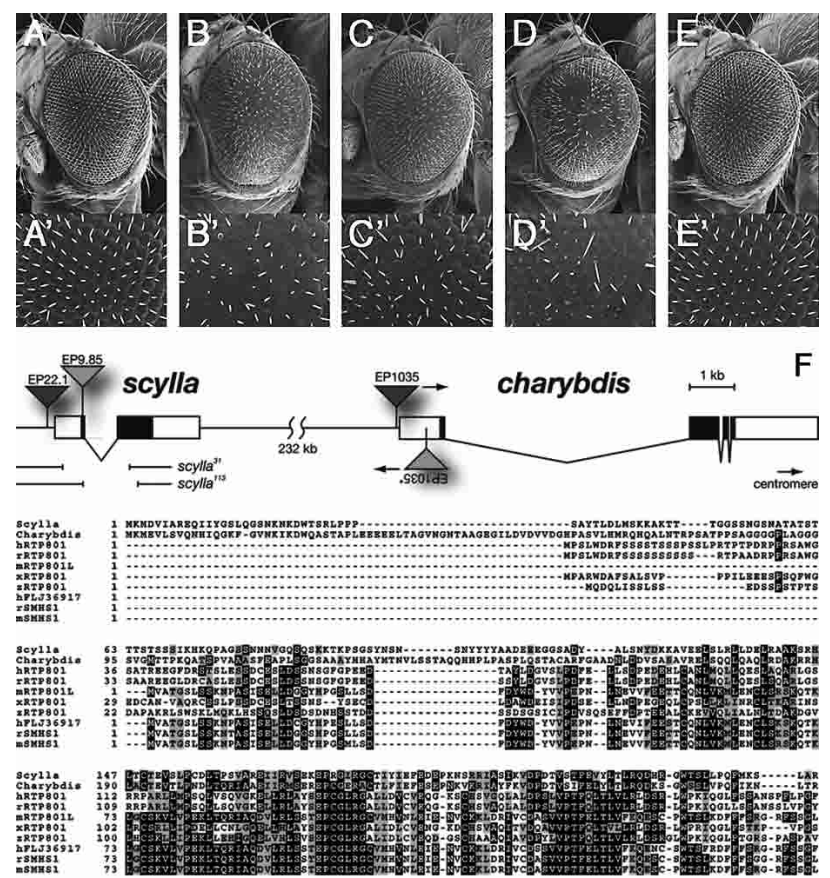

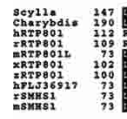
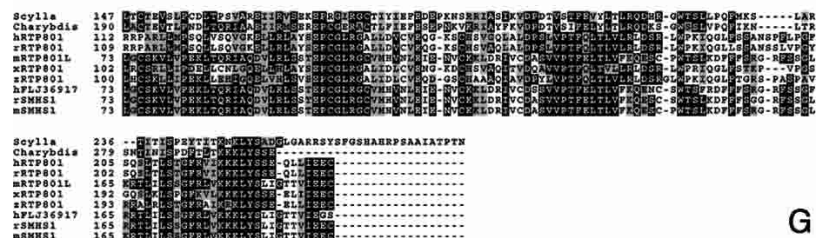

G

Figure 1. Overexpression of scylla and its paralog charybdis suppresses the hyperactivity of the Inr pathway. $(A-E)$ scylla $(C)$ and/or charybdis $(D)$ overexpression (achieved by EPScy and EPchar, respectively) suppress the PKB/PDK1-dependent big eye phenotype $(B)$. Genotypes: y $w ; G M R-G a 14 /+\left(A, A^{\prime}\right)$; y w; GMR-Gal4 UAS-PKB $/+;$ EP837 ( $U A A S-P D K 1) /+\left(B, B^{\prime}\right) ;$ y w; GMR-Gal4 UAS-PKB/+; EP837/EPscy $\left(C, C^{\prime}\right) ;$ y w; GMR-Gal4 UAS-PKB/+; EP837/EPchar (D,D'); y w; GMR-Gal4, UAS-PKB/+; EP837/EPscy EPchar $\left(E, E^{\prime}\right) .(F)$ Genomic organization of scylla and charybdis and corresponding mutant alleles. (G) Several homologs of Scylla/Charybdis are present in humans (h), rat (r), mouse $(\mathrm{m})$, Xenopus $(\mathrm{x})$, and zebrafish $(\mathrm{z})$. Charybdis bears a coiled-coil domain (amino acids 168-188) not predicted in Scylla. However, the evolutionarily most highly conserved, Cterminal part of the gene family lacks similarities to known protein domains.

charybdis under control of the GMR-Gal4 driver was observed by acridine orange staining (data not shown). This suggests that apoptosis is not the cause for the eye size reduction. Thus, scylla and charybdis overexpression antagonizes the growth-promoting effects of PKB/ PDK1 and is sufficient to negatively regulate growth.

scylla and charybdis are both expressed during embryogenesis in dynamic, partially overlapping patterns. In contrast to the broadly expressed scylla mRNA, charybdis transcripts are predominantly restricted to neurons of the CNS and PNS as assessed by mRNA in situ hybridization. During late larval stages scylla mRNA is uniformly expressed without apparent tissuespecific distribution, whereas charybdis mRNA expression could not be detected in third instar imaginal disks (data not shown).

\section{Scylla and Charybdis belong to an evolutionarily conserved protein family}

scylla codes for a 280 -amino acid polypeptide with a predicted molecular weight (MW) of $\sim 31 \mathrm{kDa}$, and the Charybdis protein contains 299 amino acid residues (MW $\sim 32 \mathrm{kDa})$. Since EP9.85 is located in the coding region of scylla, thus generating a Scylla protein with an $\mathrm{N}$-terminal truncation of 12 amino acids, we tested whether a UAS-scy transgene encoding the truncated form of Scylla behaves as the full-length protein. Overexpression of UAS-scy $y^{\Delta 1-12}$ and UAS-scy ${ }^{w t}$ showed the same effects as EPscy (data not shown), indicating that amino acids 1-12 are dispensable for the growth-suppressing function of Scylla.

Homologs of Scylla/Charybdis exist throughout the animal kingdom including humans, rat, mouse, Xenopus, and zebrafish. Reminiscent of the situation in Drosophila, mammals possess several paralogous proteins with homology to Scylla/Charybdis. At least two homologs (RTP801/REDD1 and FLJ3691, a hypothetical protein presumably corresponding to REDD2 [Ellisen et al. 2002]) exist in humans, two (RTP801 and SMHS1) in rat, and three (RTP801L, Dig2, and SMHS1) in mice. The overall homology is highest toward the $\mathrm{C}$ terminus (Fig. 1G). Charybdis contains a predicted coiled-coil structure (amino acids 168-188).

In mammals, RTP801/REDD1 and other members of the family are induced upon various forms of cellular stress including hypoxia, DNA damage, and dexamethasone treatment (Ellisen et al. 2002; Shoshani et al. 2002; Wang et al. 2003). In fact, RTP801/REDD1 is a direct target of HIF-1, a heterodimeric transcription factor that plays a pivotal role for survival in response to hypoxia (Shoshani et al. 2002). Furthermore, RTP801/REDD1 is controlled by p53 and p63 (Ellisen et al. 2002). Depending on the experimental setup and cell context, RTP801 overexpression either inhibits or increases apoptosis, suggesting a complex regulation and/or dependence on the developmental program of the cell (Shoshani et al. 2002).

\section{Scylla and Charybdis inhibit growth and are} important under hypoxic conditions

To investigate the function of Scylla and Charybdis in more detail, we generated loss-of-function mutations in both genes and complemented the analysis with overexpression studies.

Partial scylla deletions were obtained by imprecise excisions of EP9.85, which is integrated in the scylla open reading frame (ORF) and therefore already represents a scylla allele (hereafter named $s c y^{E P 9.85}$ ) (Fig. 1F). For charybdis, we used a local hop strategy of EPchar to obtain char ${ }^{180}$, constituting a new EP insertion $\left(E P 1035^{*}\right)$ in the charybdis $5^{\prime}$-untranslated region (UTR) plus the original EPchar (see Materials and Methods). Quantitative real time-PCR showed that in char $^{180}$ homozygotes, charybdis mRNA expression is decreased to $\sim 25 \%$ of wild-type levels (data not shown). We assume 
that this charybdis allele is a strong hypomorph, as mRNA levels were only slightly more reduced (to $23 \%$ or $15 \%$, respectively) when RNA was extracted from flies heterozygous for char $^{180}$ over either one of two independent deficiencies uncovering charybdis and scylla (data not shown).

All scylla mutant combinations and the char ${ }^{180}$ homozygotes are viable and fertile without apparent mutant phenotype. scylla and char ${ }^{180}$ mutant animals have the same weight as control flies. Measurement of wing size and hair density in the adult wing of scylla mutants revealed no differences in cell size and cell number as compared to control animals (data not shown). We created scylla loss-of-function clones in imaginal disks using FLP/FRT-mediated mitotic recombination to test the effect on growth properties of the mutant tissue. One would expect a growth advantage of cells in clones lacking a bona fide negative growth regulator, as is the case for PTEN. However, larval scylla mutant clones were the same size as their wild-type sister clones. Likewise, clones obtained in adult eyes revealed no increase in cell size of scylla or char ${ }^{180}$ mutant ommatidia (data not shown). Thus, loss of Scylla or Charybdis function is dispensable for growth under normal conditions. It is conceivable that Scylla and Charybdis act in a redundant manner. Therefore, it was important to create scylla charybdis double mutants.

We combined char ${ }^{180}$ with three of our scylla alleles by meiotic recombination. All double-mutant scylla charybdis combinations produced viable adult flies. Weight analysis of heteroallelic scylla charybdis flies demonstrated that simultaneous loss of Scylla and Charybdis significantly increases body weight. Consistent results were obtained by combining one copy of scy $^{E P 9.85 / 31 / 113}$ char ${ }^{180}$ and the deficiency $D f(3 L)$ vin4

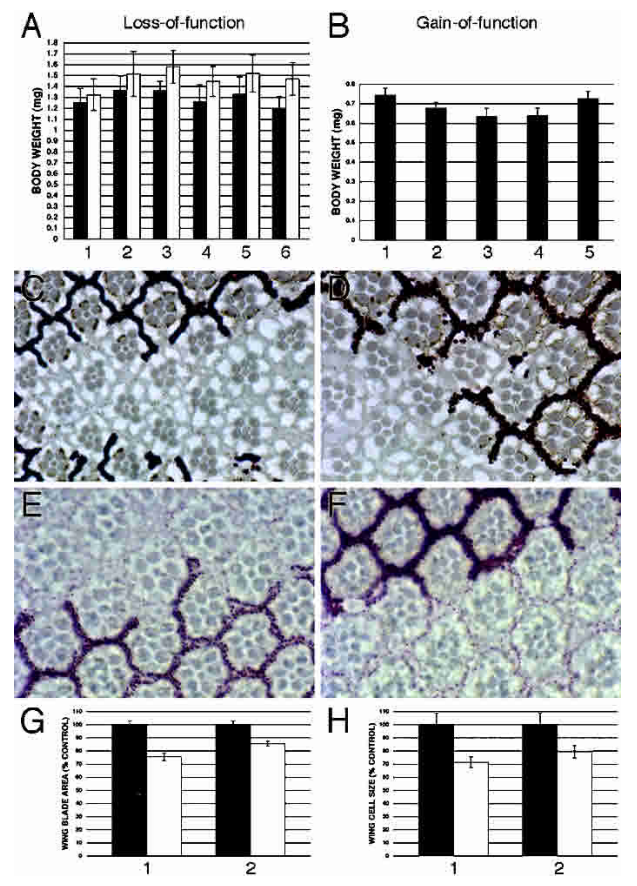

uncovering scylla and charybdis. Mutant females were on average $6 \%-23 \%$ and males $9 \%-17 \%$ heavier than control flies (Fig. 2A; data not shown). Conversely, ubiquitous scylla/charybdis overexpression using the Act5CGal4 driver generated flies that are decreased in size and weight $(15.1 \%$ using EPscy and $14.3 \%$ using UAS-char\#53) (Fig. 2B, data only shown for males). The majority of scylla/charybdis-overexpressing flies eclosed with a minor delay (0.5-1 d) (data not shown).

To assess whether charybdis/scylla overexpression affects cell size, we generated scylla and charybdis gainof-function flip-out clones in the eye, marked by the absence of the red pigment. A moderate reduction in cell size was observed in cells overexpressing scylla or charybdis (Fig. 2C,D). Ommatidia overexpressing scylla

Figure 2. Scylla and Charybdis inhibit growth. (A) Simultaneous loss of Scylla and Charybdis leads to an increase in body weight. Control flies (black bars) are represented by either of the two possible double mutants over the TM3 balancer chromosome (first three black columns) or the deficiency chromosome (Df(3L)vin4) over TM3 (three last black columns) and were derived from the same vial as the heteroallelic double-mutant flies, $p<0.009$ using Student's $t$-test (two-tailed). Between 32 and 65 flies were weighed per genotype. Genotypes (only white bars indicated) are as follows: y w; $s c y^{113} \operatorname{char}^{180} / s c y^{E P 9.85}$ char $^{180}$ (1); y w; scy ${ }^{31}$ char $^{180} /$ scy $^{E P 9.85}$ char $^{180}$ (2); y w; scy ${ }^{31}$ char $^{180} /$ scy $^{113}$ char $^{180}(3) ; y$ w/+; scy ${ }^{E P 9.85}$ char $^{180} / D f(3 L)$ vin4 (4); y w/+; scy ${ }^{113}$ char $^{180} / D f(3 L)$ vin4 (5); y w/+; scy ${ }^{31}$ char $^{180}$ / $D f(3 L)$ vin4 (6). (B) Ubiquitous scylla and charybdis overexpression generates smaller flies that have reduced body weights. In all our overexpression studies, we obtained the strongest effects using EPscy or UAS-char\#53, driving scylla and charybdis, respectively. A representative experiment of three independent weighing analyses is shown $\mid n=35$ for each genotype; $p<0.0001$ for UAS-scy\#2, EPscy, UAS-char\#53, and $p<0.02$ for EPchar). Data are only shown for males, but significant weight reduction is also observed in females. Genotypes are as follows: y w; Act5CGal4/+ (control) (1); y w; UAS-scy\#2/+; Act5CGal4/+ (2); y w; Act5CGal4/EPscy (3); y w; Act5CGal4/ UAS-char\#53 (4); y wAct5CGal4/EPchar (5). (C-F) Tangential sections through the adult eye showing photoreceptor and associated ommatidial cells. Clones of cells either overexpressing scylla/charybdis or lacking the function of both are recognizable by the absence of red pigment. scylla-overexpressing cells $(C)$ or charybdis-overexpressing cells $(D)$ in the eye are smaller than neighboring wild-type cells, and no patterning defects are observed. Conversely, scylla charybdis double-mutant cells show a mild increase in cell size $(E, F)$. Genotypes are as follows: y $w$ hsflp; GMR $>w^{+}>$Gal4/EPscy $(C) ;$ y w hsflp; UASchar\#56/+; GMR > $w^{+}>$Gal4/+ (D); y w hsflp; FRT80 scy ${ }^{113}$ char $^{180 / F R T 80 ~ w^{+}(E) \text {; y w hsflp; FRT80 } \text { scy }^{E P 9.85} \text { char }^{180} / \text { FRT80 }}$ $W^{+}(F) .(G, H)$ Quantification of wing cell size and cell number of flies overexpressing scylla. Hair density in a defined square area next to the junction of the posterior cross-vein and vein five was determined, and from this number cell size was calculated. The cell number corresponds to the ratio of total wing area and cell size. scylla overexpression reduces only cell size but not cell number. Black bars always represent the control (y w; Act5CGal4/+), and white bars represent scylla overexpression (y w; Act5CGal4/EPscy). Numbers indicate the sex: 1 for males, and 2 for females. We analyzed 10 wings of each genotype. 
or charybdis exhibit no patterning defects. On the other hand, simultaneous removal of Scylla and Charybdis in clones of photoreceptor cells resulted in slightly enlarged cells (Fig. 2E,F). Consistently, when most of the head capsule and the eyes were made homozygous by means of the eyflp/FRT system in an otherwise heterozygous mutant background, a mild big head phenotype was generated in the double mutant but not in either single mutant (Supplementary Fig. S1).

The gain-of-function clonal analysis in the eye showed that cell size is reduced upon forced scylla/charybdis expression, but it did not address the question whether cell number is affected. To clarify this issue, the wing size and cell number of flies that ubiquitously overexpress scylla were measured. The insect wing is a doublelayered epithelial structure, and each cell in the wing secretes a single hair (trichome). Therefore, by counting the number of trichomes per defined area, hair density can be taken as a measure for cell number. Overall wing size was reduced by $\sim 25 \%$ in males or $\sim 15 \%$ in females overexpressing scylla (Fig. 2G). By extrapolating the number of cells per measured area, we found that cell size is decreased by $29 \%$ in males and $~ 21 \%$ in females (Fig. 2H). We conclude that the size reduction brought about by overexpressing scylla is caused by a reduction in cell size. Cell density is even slightly increased $(5.8 \%$ in males, $7.6 \%$ in females) (data not shown). Our data show that Scylla and Charybdis have a growth-inhibitory role and that they share some functional redundancy.

RTP801/REDD1 was shown to be induced by hypoxia (Shoshani et al. 2002). This prompted us to investigate the effects of hypoxia on the scylla charybdis double mutants. scylla charybdis mutant larvae were raised on normal food at room temperature in a hypoxia chamber containing $9 \%$ oxygen during their entire development. In general, control flies as well as scylla charybdis homozygotes were 3-4 d delayed in development under these hypoxic conditions. However, whereas adult homozygous scylla charybdis double mutants could readily be recovered under standard culture conditions in normoxia, homozygous mutants of three independent scylla charybdis allelic combinations (char ${ }^{180}$ in combination with $s c y^{31}, s c y^{113}$, or $s c y^{E P 9.85}$ ) were strongly underrepresented compared to normoxic conditions. We also observed the appearance of an increased number of dead pupae in the vials (data not shown). The scylla ${ }^{113}$ char ${ }^{180}$ double-mutant combination had the strongest effect, and only two escapers (out of 326 scored flies) hatched, whereas under normoxia flies with this genotype were recovered with nearly the expected Mendelian ratio. The eclosed homozygotes raised under hypoxia did not show obvious morphological defects.

Thus, whereas simultaneous loss of Scylla and Charybdis under normoxic conditions results in a slight increase in growth, their absence under reduced oxygen concentrations severely compromises larval development. This indicates that Scylla and Charybdis have a critical function for survival under hypoxic conditions. scylla and charybdis are up-regulated under hypoxic conditions and scylla is a target of Drosophila HIF-1

The transcription factor HIF-1 is the key regulator of changes in gene expression in response to hypoxia (Bruick 2003). It consists of two bHLH-PAS domain protein subunits (HIF-1 $\alpha$ and HIF-1 $\beta$ ). Under conditions of low oxygen, the HIF-1 protein complex is stabilized and binds to Hypoxia Response Elements (HRE), short regulatory DNA sequences (core recognition sequence $5^{\prime}$ TACGTG-3') located in the genomic region of target genes. Both the scylla and charybdis loci possess several HREs. Since RTP801/REDD1, a mammalian homolog of scylla and charybdis, is a direct target gene of HIF-1 and is induced under hypoxic conditions, we wondered whether this function is evolutionarily conserved. We subjected wild-type larvae to hypoxia (between $2 \%$ and $5 \% \mathrm{O}_{2}$ ) and checked for the induction of scylla and charybdis expression. It is mainly the endoreplicative tissue such as fat body, gut, salivary glands, and tracheae that respond to changes in oxygen concentrations (Lavista-Llanos et al. 2002). scylla mRNA expression was up-regulated in the larval fat body and in the gut after hypoxia (Fig. 3B; data not shown). charybdis, on the other hand, was mildly induced in the midgut but not in the fat body (Fig. 3D; data not shown). We also tested whether hypoxia had an effect on Scylla protein levels and distribution. To detect the endogenous Scylla protein, we took advantage of a transgenic Scylla-reporter line (a so-called protein trap line). This protein trap line bears a promoter-less green fluorescent protein (GFP)reporter transgene in the scylla locus generating a Scylla-GFP fusion protein (Morin et al. 2001). Scylla-GFP is expressed in most larval tissues. Under normoxic conditions, nuclear accumulation of Scylla protein is observed in some cells of the endoreplicative tissue (data not shown). Consistent with our mRNA data, upon exposure of third instar larvae to various hypoxia conditions, we observed an up-regulation and nuclear localization of Scylla protein in the fat body (data not shown) and in the gut (Fig. 3K-P).

In Drosophila, the bHLH-PAS family comprises Period (Per), Trachealess (Trh), Single-minded (Sim), Spineless (Ss), Dysfusion (Dys), Tango (Tgo), and Similar (Sima). Tgo is the ubiquitously expressed HIF- $1 \beta$ ortholog, which dimerizes with any of the $\alpha$-subunits. Sima has been shown to fulfill analogous functions to its mammalian homolog HIF-1 $\alpha$ (Lavista-Llanos et al. 2002).

To test whether scylla/charybdis transcription is regulated by bHLH-PAS proteins that recognize the same DNA stretch, we overexpressed sim, trh, or sima together with tgo using the Lsp2Gal4-driver that is active specifically in the fat body during the third larval stage. For Sima, we used a form lacking the oxygen-dependent degradation domain (ODD), rendering it refractory to proteolytic destruction under normoxic conditions. Only the coexpression of tgo and sima induced scylla but not charybdis expression as assessed by mRNA in situ hybridization (Fig. 3G,J; data not shown). This does not preclude, however, the possibility that charybdis is a 


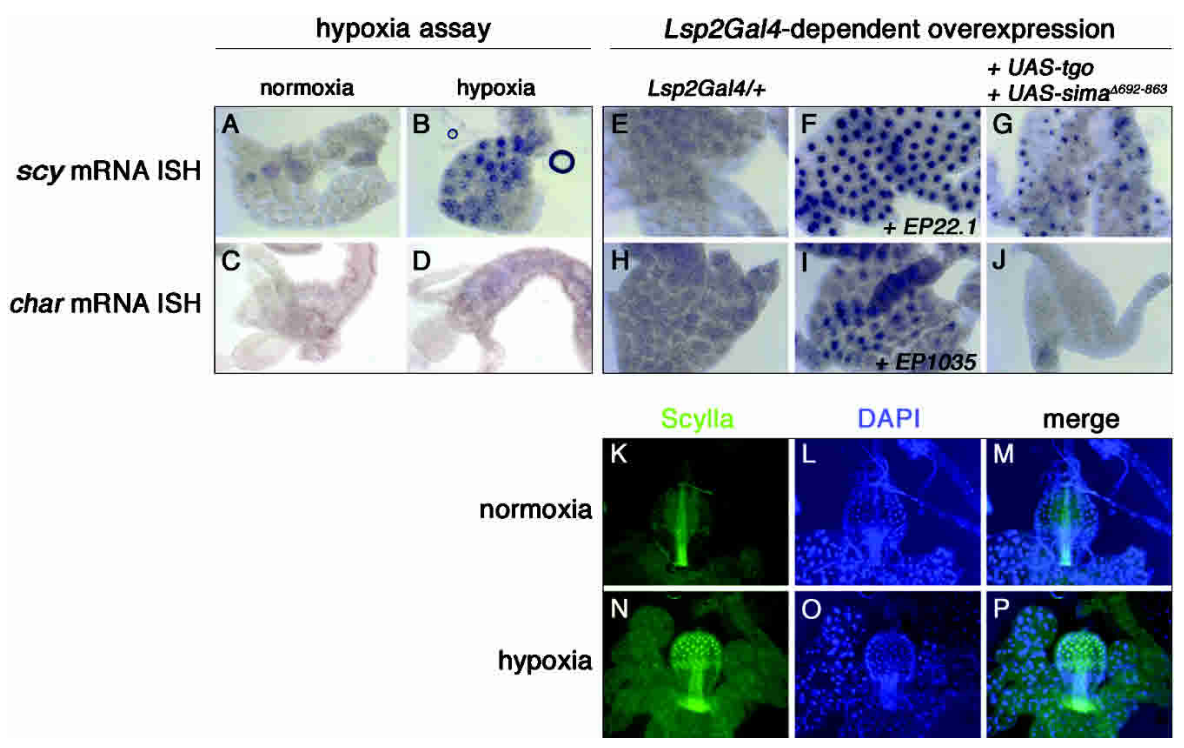

Figure 3. scylla and charybdis are induced by hypoxia, and scylla is a target of Drosophila HIF-1. $(A-D)$ Larvae were incubated in a hypoxia chamber for either $17 \mathrm{~h}$ under $2 \% \mathrm{O}_{2}$ or for $7 \mathrm{~h}$ under $2.8 \% \mathrm{O}_{2}$ conditions leading to the induction of scylla $(B)$ and charybdis $(D)$ expression as assessed by mRNA in situ hybridization (ISH). Since scylla mRNA is detected in the gut under normoxia, it has been difficult to assess whether scylla transcript levels are further induced under hypoxia (data not shown). (E-J) Directed coexpression of Tgo and Sima in the fat body up-regulates scylla $(G)$ but not charybdis $(J)$ transcription. $(F, I)$ Positive controls for scylla and charybdis, respectively. $(K-P)$ Scylla protein localizes to the nucleus and is up-regulated in the proventriculus $(N)$ and the fat body (not shown) in hypoxia. Genotypes are as follows: y $w(A-D) ;$ y w; Lsp2Gal4/+ $(E, H) ;$ y w; Lsp2Gal4/EPscy $(F)$; y w; UAS-tgo/+; Lsp2Gal4/UAS$\operatorname{sima}^{\Delta 692-863}(G, I) ; y w$; Lsp2Gal4/EPchar $(I)$. (K-P) Scylla fly trap larvae grown in normoxia $(K-M)$ or incubated in hypoxia $\left(2.8 \% \mathrm{O}_{2}\right.$ for $8 \mathrm{~h} ; N-P)$.

target of Tgo-Sima as we detected its endogenous induction upon hypoxia only in the gut but not in the fat body. Since neither expression of trh with tgo nor sim induced scylla or charybdis expression, the regulation of scylla by the Tgo-Sima heterodimer is specific. Thus, scylla and charybdis, like their mammalian homolog RTP801/ $R E D D 1$, are induced by hypoxia, and at least scylla appears to be a direct target gene of the HIF-1 homolog Tgo-Sima.

\section{Scylla acts downstream of PKB but upstream of TSC}

Although loss of Scylla function does not produce a mutant phenotype on its own, we tested whether it would alter the $P K B / P D K 1$ overexpression eye phenotype. Indeed, loss of Scylla function enhanced the PKB/PDK1 overgrowth phenotype (Fig. 4B,C). Thus, Scylla is essential for attenuating the increased growth in response to hyperactivation of the Inr pathway. Furthermore, loss of Scylla partially suppressed the growth reduction associated with reduced PKB function as assessed by comparing weights of $P K B^{3}$ single mutants to $s c y^{31} P K B^{3}$ double mutants (Fig. 4D). In contrast, complete loss of Scylla in a heteroallelic $S 6 K$ combination did not rescue the $S 6 K$ single mutant phenotype indicating that $S 6 K$ is epistatic over scylla (Fig. 4E).

Moreover, overexpression of scylla and charybdis not only suppressed the growth phenotype caused by overactivation of the Inr pathway in the eye but to a certain extent also rescued the lethality associated with the ubiquitous increase in Inr pathway activity due to either overexpression of $P K B$ or loss of PTEN. scylla rescued the male-specific lethality caused by ubiquitous expression of $P K B$ and organismal lethality associated with the partial but not complete loss of PTEN function. Similarly, $P K B$-associated male lethality was also rescued by charybdis overexpression (Supplementary Tables 1, 2). This indicates that scylla and charybdis have the capacity to act as potent negative regulators of insulin signaling downstream of PKB and PDK1.

Several lines of evidence suggest that Scylla and Charybdis act upstream of TSC and Rheb. Tsc1/2 mutant flies can be rescued to adulthood by reducing S6K signaling (Radimerski et al. 2002a), and a mere reduction of one TOR copy in a Tsc1 mutant context results in a rescue to the pupal stage (Gao et al. 2002). We examined whether ubiquitous scylla overexpression could rescue the larval lethality of heteroallelic Tsc1/2 mutant combinations (Tsc1 $1^{2 G 3} / T s c 1^{Q 87 X}$ and $\left.T s c 2^{56} / T_{s c 2}{ }^{192}\right)$ using the daGal4 or Act5CGal4 drivers in combination with a $U A S$-scy transgene or EPScy at $18^{\circ} \mathrm{C}, 25^{\circ} \mathrm{C}$, and $29^{\circ} \mathrm{C}$. Ubiquitous overexpression of scylla/charybdis in a Tsc1/2 mutant background did in no case extend larval development beyond first/second instar, and these larvae died at the same time as Tsc1/2 mutants. Moreover, the big head phenotype of $T s c 2^{192}$ (and Tsc2 $2^{56}$ ) induced by the eyflp/FRT system was not further enhanced in scy ${ }^{E P 9.85}$ char $^{180}$ Tsc2 triple-mutant heads (Fig. 4F,G). We have shown before (Supplementary Fig. S1) that 

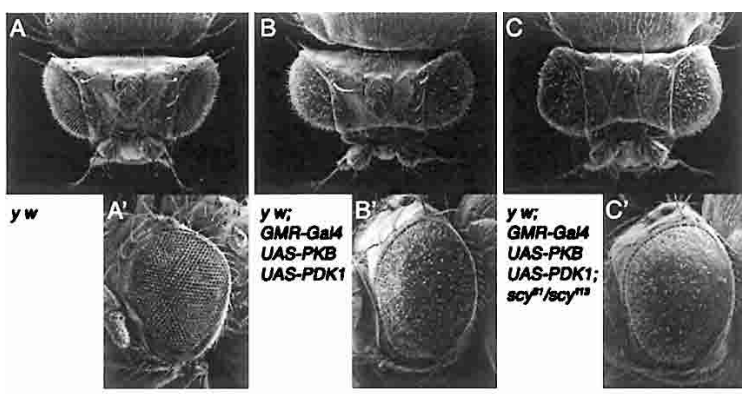

D
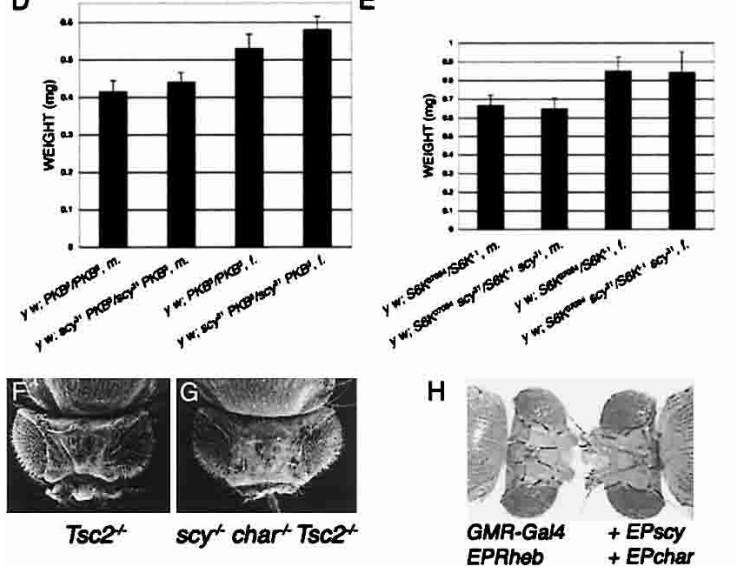

Figure 4. Scylla attenuates growth in response to elevated Inr pathway activity downstream of PKB but upstream of TSC. (A$C)$ A $P K B / P D K 1$-overexpression eye phenotype is enhanced in a scylla mutant background. Genotypes are as follows: yw $\left(A, A^{\prime}\right)$; y w; GMR-Gal4 UAS-PKB UAS-PDK1/+ $\left(B, B^{\prime}\right)$; y w; GMR-Gal4 UAS-PKB UAS-PDK1/+; scylla $a^{31} /$ scylla $^{113}\left(C, C^{\prime}\right)$. $(D)$ Loss of scylla partially suppresses the weight loss of homozygous $P K B^{3}$ mutants. Weight increase in the double mutants versus $P K B^{3}$ single mutants is $\sim 6 \%$ (males) and $10 \%$ (females) for this experiment. One representative of four independent weighing experiments is shown; $p<0.0001, n=60$ (males) and 90 (females). (E) No difference in body weight between a hypomorphic $S 6 \mathrm{~K}$ mutant combination and S6K scylla double mutants was observed $(n=30) .(F, G)$ scylla charybdis Tsc2 triple-mutant heads resemble Tsc2 single mutants and do not show additive growth effects, indicating that Scylla and Charybdis act upstream of Tsc2. Genotypes are as follows: y w eyflp; FRT80 gig $^{192} / F R T 80$ cl3L $\mathrm{W}^{+}(F)$; y w eyflp; FRT80 scy ${ }^{E P 9.85}$ char $^{180}$ gig $^{192} /$ FRT80 cl3L $W^{+}(G)$. (H) A Rheb-dependent bulging eye phenotype cannot be suppressed by scylla/charybdis coexpression. Genotypes are as follows: y w; GMR-Gal4/+; EPRheb/+ (left); y w; GMR-Gal4/+; EPRheb/EPscy EPchar (right).

heads composed almost entirely of scylla charybdis double-mutant cells are enlarged. Conversely, GMRGal4-driven co-overexpression of Tsc1, Tsc2, and scylla or charybdis in the eye did not further reduce the small eye phenotype induced by coexpression of Tsc1 and Tsc2 on their own (data not shown). The absence of an additive growth effect upon loss of Tsc2, scylla, and charybdis or overexpression of Tsc1/2 and scylla or charybdis suggests that they function in the same pathway. These results are consistent with the idea that Scylla and Charybdis act upstream of the TSC complex (see also next section). Our conclusion is further supported by the fact that neither a Rheb-dependent bulging eye phenotype nor organismal lethality could be suppressed by scylla/charybdis coexpression (Fig. $4 \mathrm{H}$; data not shown).

\section{Scylla decreases S6K but not PKB activity}

To test whether the placement of Scylla between PKB and TSC can be corroborated biochemically, we investigated the effect of scylla overexpression on PKB and S6K activity.

We tested PKB activity of adult female heads overexpressing scylla or charybdis in conjunction with $P K B$ and PDK1 under control of the GMR-Gal4 enhancer. The same experimental setup has previously been used to demonstrate that PDK1 increases PKB activity (Cho et al. 2001). Total fly head protein was extracted and PKB activity was assayed by incorporation of ${ }^{32} \mathrm{P}$-labeled phosphate into a synthetic PKB substrate (Crosstide, CT). Although scylla/charybdis overexpression substantially suppressed the PKB/PDK1-induced bulging eye phenotype (Fig. 1C), PKB activity was not reduced in these eyes (Fig. 5A). Moreover, PKB activity was also unaffected in a scylla $a^{-/-}$background (Fig. 5B).

These results are consistent with the placement of Scylla downstream of PKB. To test the effect of Scylla on
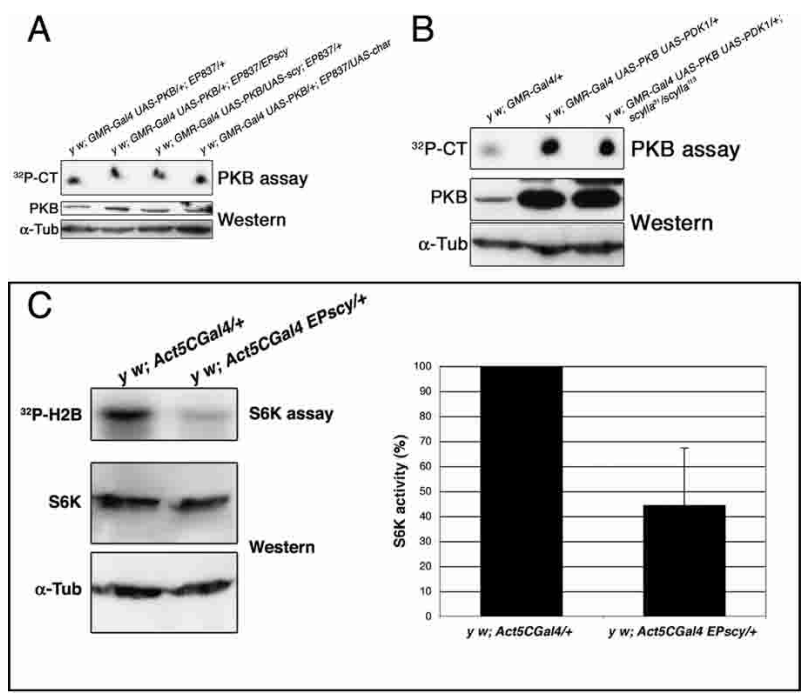

Figure 5. Scylla reduces S6K activity, but neither Scylla nor Charybdis down-regulates PKB activity. (A) Head extracts of flies overexpressing $P K B$ and $P D K 1$ in conjunction with either scylla or charybdis in the eye were assayed for PKB activity. No reduction could be detected (experiment has been performed twice). Genotypes are indicated above the autoradiograph. (CT) Crosstide, a synthetic PKB substrate. (B) Eye-specific PKB/ $P D K 1$ coexpression in a scylla mutant background does not lead to elevated PKB activity (three experiments have been done). (C) Ubiquitous scylla overexpression decreases S6K activity by $56 \%$ on average, $p<0.006$. S6K activity of second instar larvae was determined by the incorporation of radioactively labeled phosphate into the H2B substrate. Control (Act5CGal4/+) activity was set to $100 \%$. Five independent experiments were performed. 
S6K activity, second instar larvae expressing scylla under the control of Act5CGal4 were collected, and larval extracts were assayed for S6K activity. On average, S6K activity was down-regulated by $>50 \%$ (Fig. 5C). Although there may also be a slight reduction in total S6K protein levels, this effect cannot account for the much stronger reduction in S6K activity. Taken together with the genetic evidence presented above, these results strongly support the argument that Scylla acts between PKB and TSC to regulate S6K activity. Furthermore, in an accompanying paper, Brugarolas et al. (2004) provide direct biochemical evidence that a functional TSC complex is required for RTP801/REDD1 to affect S6 phosphorylation. Altogether, these data indicate that Scylla functions upstream of TSC.

\section{Scylla and Charybdis prolong life span under starvation conditions}

Zinke et al. (2002) have performed a whole-genome DNA microarray analysis of 2-d-old larvae ( $48 \mathrm{~h} \mathrm{AEL)} \mathrm{grown} \mathrm{on}$ normal food that were subsequently subjected to a starvation regime for different time periods. Under these conditions, upon $12 \mathrm{~h}$ of starvation, scylla and charybdis expression were found to be on average 6.3 times and 4.6 times up-regulated, respectively (downloadable Supplemental Material at http://www.fzk.de/embo). Therefore, we tested the effects of starvation on the viability of scylla and charybdis mutants, as well as on flies overexpressing both genes by exposing adult flies to a wateronly diet. Various scylla heteroallelic combinations did not show elevated susceptibility to starvation (data not shown). However, char ${ }^{180}$ mutants lived significantly shorter lives than control flies, suggesting that Charybdis has a protective effect for the animal under nutrientdeprived conditions (Fig. 6A). Strikingly, forced expression of scylla/charybdis extended mean life span by up to twofold (Fig. 6B). We analyzed lipid and glycogen content of these flies to see whether energy stores were altered. Indeed, flies overexpressing scylla and/or charybdis showed significantly elevated lipid levels (Fig. 6C). We also measured glycogen levels but could not detect any statistically significant changes, although there was a tendency toward increased glycogen content (data not shown).

\section{Discussion}

Here we provide evidence that two related proteins, Scylla and Charybdis, are negative modulators of Inr/ TOR signaling in response to different external stress situations including hypoxia and starvation. scylla and charybdis single mutants do not show obvious growth phenotypes. scylla charybdis double-mutant flies are also viable and fertile and exhibit a slight increase in body size. Viability of the double mutants is strongly reduced, however, when they are reared under hypoxic conditions. Thus, although Scylla and Charybdis are largely dispensable for normal development, they have a critical role for the endurance of prolonged hypoxia. We show that scylla is transcriptionally induced as a target
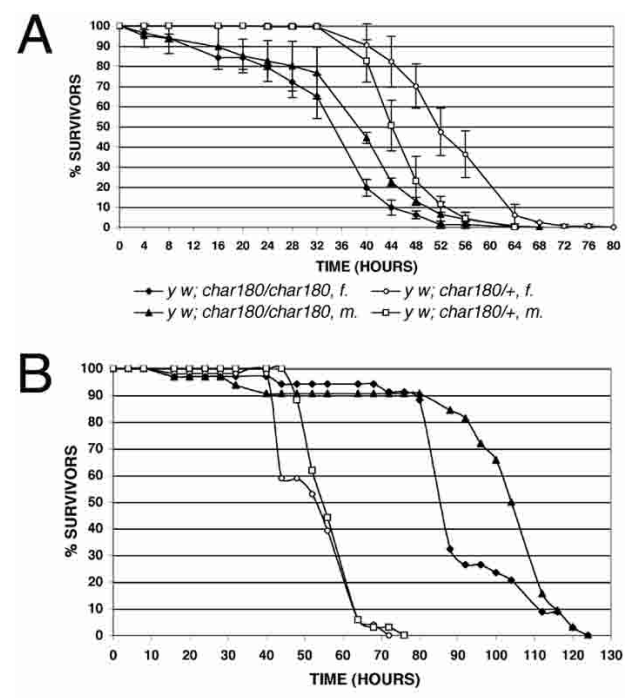

$\rightarrow y w$ : daGal/4/EPSCy EPchar, $t, \rightarrow-y w ; d a G a / 4 / 4, t$ $\rightarrow y w$ daGal4/EPSCy EPChar, $m$. - - $-y w ;$ daGal4/t, m.

C

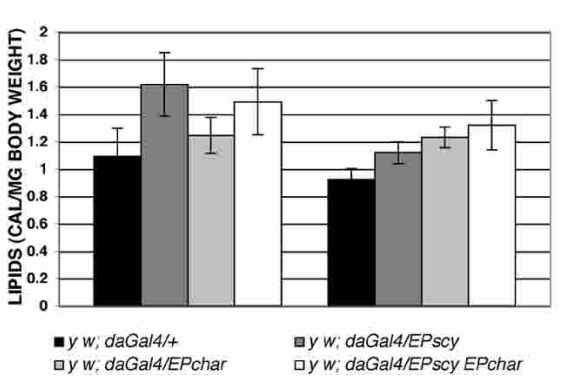

Figure 6. Scylla and Charybdis prolong life span under starvation conditions. (A) Homozygous char ${ }^{180}$ mutants are more susceptible to starvation than control animals. The average and standard deviations of three independent experiments are shown $\left(n=114\right.$ for char $^{180} /$ char $^{180}, \mathrm{~m}$.; $n=145$ for char $^{180} /+, \mathrm{m}$.; $n=82$ for $\operatorname{char}^{180} /$ char $^{180}, \mathrm{f}_{\text {.; }}$ and $n=127$ for $\operatorname{char}^{180} /+$, f.). $(B)$ Two- to three-day-old adult flies coexpressing scylla and charybdis were starved, and survivors were counted every $4 / 8 \mathrm{~h}$. Simultaneous overexpression of both proteins strongly extended life span compared to control flies. A representative example of three independent experiments is shown. $(C)$ Ubiquitous expression of scylla, charybdis, and/or both together using the daGal4 driver is accompanied by elevated lipid levels in males (left bar cluster) and females (right bar cluster; $p<0.065$ for daGa14/EP1035, m.; for all other genotypes $p<0.0009$; $n=10$ ). (m.) Males; (f.) females.

of Drosophila HIF-1 (the Tango-Similar dimer) and that scylla and charybdis are up-regulated under hypoxic conditions like their mammalian homolog RTP801/ REDD1. Furthermore, we show that Scylla negatively regulates Inr/TOR signaling by reducing S6K but not PKB activity.

scylla/charybdis and their orthologs are stress-induced genes

RTP801 was described as a hypoxia/HIF-1-inducible factor with a role in apoptosis (Shoshani et al. 2002). We 
find that scylla/charybdis, like their mammalian homo$\log$, are induced by hypoxia, and that scylla is a direct target of Drosophila HIF-1. However, we have no indication that scylla/charybdis overexpression promotes cell death. Coexpression of the caspase inhibitors p35 or DIAP1 did not rescue the small eye phenotype induced by expression of either scylla or charybdis in the eye. Moreover, acridine orange staining revealed no increased cell death upon scylla/charybdis coexpression (data not shown). Accordingly, we never observed signs of necrotic eye tissue upon scylla/charybdis overexpression.

Dig2, a murine Scylla/Charybdis homolog, is also a stress-responsive protein induced by a variety of treatments including dexamethasone, thapsigargin, tunicamycin, and heat shock (Wang et al. 2003). Together with the finding by Zinke et al. (2002) that scylla/charybdis expression is increased during starvation conditions and our analysis, showing that Scylla and Charybdis act as growth inhibitors, these data support a model wherein Scylla and Charybdis, induced by stresses like hypoxia and starvation, act to dampen growth under certain stress conditions.

\section{Do Scylla and Charybdis act together?}

Overexpressing either scylla or charybdis on their own is sufficient to reduce growth. Coexpression of both proteins seemed to have a slight cooperative effect (Fig. 1G) on the PKB/PDK1-dependent eye phenotype with respect to ommatidial structure. Thus, an obvious question is whether Scylla and Charybdis bind to each other and exert their effect only in the presence of the other. Notably, eye-specific charybdis overexpression in a scylla $a^{-1-}$ background resulted in the same phenotype as in a wild-type situation (data not shown). This indicates that Charybdis can act independently of Scylla. This is further supported by their mostly nonoverlapping mRNA expression patterns. Indeed, charybdis but not scylla is expressed in neuromuscular junctions (M. Knirr and C. Schuster, pers. comm.). Moreover, under hypoxia only scylla was induced in the fat body but not charybdis, indicating that they may be differentially regulated.

Scylla/Charybdis act downstream of $P K B$ but upstream of TSC to regulate S6K activity

Several lines of evidence indicate that Scylla and Charybdis feed into the Inr pathway downstream of PKB: (1) Scylla antagonizes PKB/PDK1-induced overgrowth in the eye, but in vitro kinase assays demonstrate that Scylla and Charybdis do not reduce PKB kinase activity, nor does the loss of Scylla enhance PKB kinase activity. (2) scylla or charybdis coexpression can rescue PKB-induced developmental lethality, and ubiquitous scylla expression suppresses the lethality associated with hypomorphic PTEN mutants. (3) The weight reduction of hypomorphic $P K B^{3}$ flies is partially rescued by the simultaneous absence of Scylla function. (4) Eye-specific PKB/PDK1 expression in a scylla ${ }^{-/-}$background leads to a mild enhancement of the eye phenotype. (5) Overexpression of PTEN or $D p 110^{D N}$ does not suppress the big eye phenotype of the tester system, suggesting that our screening system identifies components that act downstream of PKB.

The S6K assay demonstrated that Scylla is capable of reducing S6K activity. Thus, Scylla acts upstream of S6K. This result is consistent with our in vivo results. (1) scylla overexpression in the wing reduces wing size by decreasing cell size but not cell number (in fact, cell number is slightly increased), and (2) a S6K scylla mutant combination has the same weight as $S 6 \mathrm{~K}$ single mutants. $S 6 \mathrm{~K}$ mutants are smaller because of a reduction in cell size but not cell number, making it distinct from other Inr signaling pathway mutants (Montagne et al. 1999). Scylla and Charybdis do not control S6K activity directly but require its upstream regulator TSC. Tsc1/2 mutants cannot be rescued by overexpression of scylla, and the big head phenotype caused by loss of TSC function is not enhanced by the absence of Scylla and Charybdis. Coexpression of scylla or charybdis and Tsc1/2 does not further decrease eye size compared to Tsc1 and Tsc2 co-overexpression on their own. Moreover, a Rheb-dependent big eye phenotype or lethality induced by ubiquitous $R$ heb expression cannot be suppressed by scylla expression. These results indicate that Scylla regulates S6K activity by acting upstream of Tsc1/2 and Rheb. This function appears to be conserved between mammals and flies because RTP801/REDD1 can reduce S6 phosphorylation only in the presence of TSC (Brugarolas et al. 2004).

Our findings indicate that scylla/charybdis overexpression mainly affects the TSC/TOR/S6K branch of the pathway downstream of PKB. The PKB-FOXO axis appears not to be influenced by Scylla and Charybdis. Eyespecific overexpression of scylla/charybdis in conjunction with FOXO was unable to induce $4 E B P$ (Supplementary Fig. S2). In contrast, simultaneous expression of FOXO and PTEN or a dominant-negative form of PI3K led to a strong induction of the reporter gene (Junger et al. 2003).

Consistent with an interplay between the Inr and TOR/S6K pathways, Inr lethality is suppressed by heterozygosity of Tsc1 (Gao and Pan 2001). Furthermore, overexpressed PKB phosphorylates and inactivates Tsc2 and thereby activates S6K (Inoki et al. 2002; Manning et al. 2002). Our finding that scylla overexpression is sufficient to rescue the lethality associated with $P K B$ overexpression indicates that the lethality caused by $P K B$ overexpression is due to the hyperactivation of the TOR/ S6K pathway. Thus, oncogenic activation of PI3K/PKB signaling seems to be mainly mediated by TOR/S6K signaling. This may explain the beneficial effect of Rapamycin treatment (or its derivatives CCl-779 and RAD001) on PTEN-deficient tumors or cells overexpressing PKB (Neshat et al. 2001; Podsypanina et al. 2001; Shi et al. 2002; Majumder et al. 2004).

\section{The TSC/TOR pathway as an integrator of growth} and metabolism

TSC and TOR receive multiple inputs reflecting the metabolic state of the cell (Hay and Sonenberg 2004). 
AMP-activated kinase (AMPK) is a heterotrimeric kinase that is activated by high AMP/ATP ratios in the cell (Carling 2004). ATP depletion induces Tsc2-phosphorylation, and it was found that AMPK could interact with and phosphorylate Tsc2 (Inoki et al. 2003b). Interestingly, loss of Tsc2 in MEFs and U2OS osteosarcoma cells under low serum and prolonged hypoxia conditions results in HIF- $1 \alpha$ accumulation and concomitantly increased expression of HIF-1 targets in a Rapamycin-dependent manner (Brugarolas et al. 2003). Arsham et al. (2003) showed that mTOR is regulated by decreased oxygen concentration resulting in a dephosphorylation of mTOR at Ser 2481, an mTOR autophosphorylation site. This effect was accompanied by reduced S6K phosphorylation but did not correlate with changes in adenine nucleotide levels and AMPK phosphorylation. Hence, these findings suggest a role for AMPK/Tsc2/mTOR in the integration of oxygen sensing/energy metabolism and growth.

\section{Model of Scylla/Charybdis function}

Frei and Edgar (2004) found mutations in the gene encoding Drosophila HIF-1 prolyl hydroxylase (Hph), the enzyme rendering HIF- $1 \alpha$ a substrate for proteasomal destruction under normoxic conditions, as dominant suppressors of a Cyclin D/Cdk4-induced bulging eye phenotype. Cells defective for $h p h$ show a growth deficit, and its overexpression stimulated growth. The authors suggested that the growth-promoting function of $\mathrm{Hph}$ is independent of HIF- $1 \alpha /$ Sima. Our results raise the possibility that the Sima target scylla is important under hypoxia for growth inhibition.

We have shown that directed expression of Tgo-Sima in the fat body induces scylla expression. That this regulation is physiologically relevant can be inferred from three findings. First, scylla is also induced under hypoxic conditions. Second, directed expression of other bHLHPAS proteins like Tgo-Trh or Sim alone did not induce scylla expression. Third, survival of flies lacking scylla and charybdis function is severely compromised under hypoxic conditions. Figure 7 summarizes our current model of Scylla and Charybdis function. scylla and charybdis are induced in response to external stress stimuli (e.g., hypoxia and starvation) to inhibit growth downstream of PKB but upstream of Tsc1/2. Scylla suppresses growth by reducing S6K activity. This could be achieved by relieving the inhibitory effect of PKB on Tsc2. Alternatively, Scylla/Charybdis could be negatively regulated targets of PKB. This is unlikely, however, since Scylla and Charybdis lack PKB consensus phosphorylation sites. AMPK, activated by drops in energy levels, may also contribute to the induction process of scylla and charybdis for growth inhibition, presumably under prolonged stress exposure. However, it is also possible that AMPK is controlled by Scylla and/or Charybdis. AMPK decreases protein synthesis by inhibition of S6K in a Rapamycin-sensitive manner, suggesting that mTOR is involved in mediating AMPK signaling (Kimura et al. 2003). AMPK also phosphorylates Tsc2, an

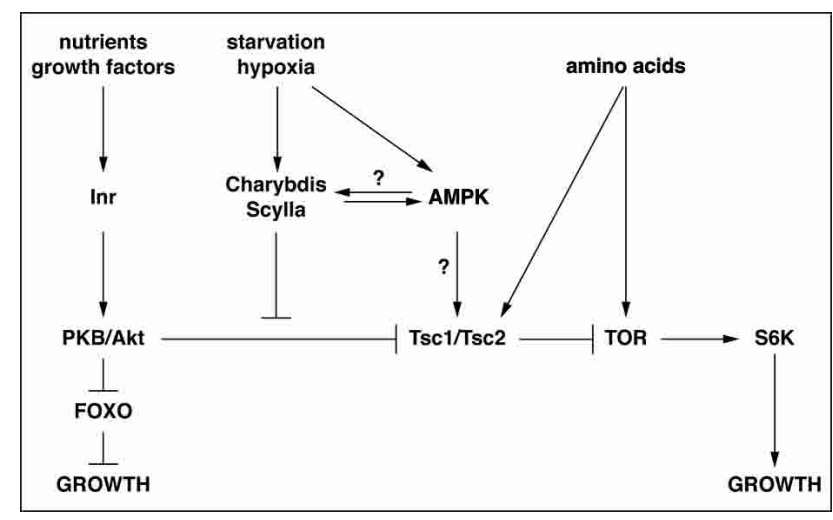

Figure 7. Model of scylla/charybdis regulation and their effects. scylla and charybdis are stress-induced, negative growth modulators that inhibit growth under adverse environmental conditions. They are likely to feed into Inr/TOR/S6K signaling downstream of PKB but upstream of TSC to relieve the inhibitory effect of PKB on the TSC complex, thereby inhibiting growth. Our results do not exclude the possibility that S6K activity also responds to stress independent of Scylla/Charybdis function. Furthermore, Scylla/Charybdis may also regulate or be regulated by AMPK. See text for details.

event important for the cellular energy response pathway (Inoki et al. 2003b).

\section{RTP801/REDD1 may act as a hypoxia-dependent tumor suppressor}

In tumors, hypoxic microenvironments are often encountered. Tumor hypoxia is associated with poor prognosis and resistance to radiation-induced cell death. $\mathrm{Mu}$ tations in the tumor suppressor von Hippel-Lindau (VHL), the subunit of an E3 ubiquitin ligase complex that recognizes proline-hydroyxlated residues in HIF- $1 \alpha$, lead to the formation of a variety of tumors including clear cell carcinomas of the kidney, pheochromocytomas, and hemangioblastomas (Safran and Kaelin 2003). VHL-defective tumors exhibit increased HIF- $1 \alpha$ expression. The induction of $R T P 801 / R E D D 1$ in cells exposed to hypoxia in tumors raises the possibility that these genes may play a role in tumor development. RTP801/REDD1 may act as a tumor suppressor. Cells having lost RTP801/ REDD1 function may not stop growing under hypoxic conditions and hence risk accumulating further mutations that promote their tumorigenic state. The analysis of RTP801/REDD1 expression or mutations in a variety of tumor cell lines should help to test this hypothesis.

\section{Materials and methods}

\section{EP element mapping and generation of transgenic flies}

The insertion sites of EP9.85 and EPscy were determined by plasmid rescue. To obtain UAS-scy, we PCR-amplified a fragment containing the coding region of scylla out of a reversetranscribed embryonic RNA pool (kindly provided by K. Nairz, University of Zurich, Switzerland); all primer sequences available on request). The PCR fragment was subcloned into the pCRII-TOPO vector using the TOPO TA cloning kit (Invitro- 
gen). The scylla cDNA was cut out of pCRII-Topo as an Asp718/ $\mathrm{XbaI}$ fragment and inserted into the pUAST vector (Brand and Perrimon 1993) to yield pJR3. At position 414 of the coding region, our sequence differs from that submitted by $\mathrm{S}$. Chauvet, C. Maurel-Zaffran, R. Miassod, N. Julliens, J. Pradel, and D. Aragnol (submitted sequence to the EMBL GenBank DDBJ databases) and results in an $\mathrm{A} \rightarrow \mathrm{G}$ exchange. However, the codon still codes for Glu and represents either a silent mutation or a polymorphism.

The shortened scylla construct UAS-scy ${ }^{\Delta 1-12}$ was PCR-generated by using pJR3 as the DNA source with an ATG translational start site introduced by PCR mutagenesis. EP9.85, inserted $36 \mathrm{bp}$ after the predicted translational start, shows the same effects as EPSCy, which lies further upstream of the scylla transcription start site. We consider it likely that the last $3 \mathrm{nt}$ of EP9.85 (i.e., ATG) serve as starter methionine to which amino acid 13 of the original Scylla protein is connected in frame.

To generate the UAS-char transgene, we ordered EST LP03309 (Research Genetics) corresponding to charybdis and checked the sequence for mutations. charybdis cDNA was excised from pOT2 as an EcoRI/XhoI fragment and inserted into the pUAST vector.

Transgenic flies were generated by P element-mediated germline transformation. Constructs were injected into $y w$ embryos. At least two independent lines could be established for each construct.

\section{Generation of mutants}

For the generation of scylla mutants, we mobilized EP9.85 (marked with $\mathrm{y}^{+}$) inserted in the scylla ORF by supplying $\Delta 2-3$ transposase. Jump starter males were mated with y $w ; D / T M 3$ females, and single F1 $y^{-}$males were crossed to $y$ w; D/TM3 virgins. Approximately 400 stocks were established, and each stock was molecularly investigated for deletions by single-fly PCR using a panel of different primer pairs. Besides the mentioned $s c y^{31}$ and $s c y^{113}$ deletions, we found three additional smaller deficiencies.

char ${ }^{180}$ was identified in a local hop screen, mobilizing the original $\mathrm{W}^{+}$-marked EPchar insertion (causing a faint orange eye color). After the mobilization, we scored animals having a darker $W^{+}$eye color than EPchar and allowed recombination to occur by crossing single females to $y w$ males. Only lines in which all the offspring consistently displayed the darker eye color (i.e., where presumably no recombination has occurred) were further analyzed by PCR using primers that would amplify the charybdis genomic locus (but not when a new EP had inserted). Out of 331 single females showing a darker eye color, 112 lines were established and analyzed by single-fly PCR. Only char $^{180}$ was identified (contains the original EPchar element plus a new inverted EP insertion [indicated as EP1035* in Fig. $1 \mathrm{~F}] ~ 450$ bp upstream of the char ORF). Quantitative RT-PCR of homozygous char $^{180}$ flies revealed a $75 \%$ reduction in mRNA levels (Q RT-PCR data available on request).

\section{Fly stocks}

The following fly stocks and transgenes have been used in the course of this study: GMR-Gal4 (gift of M. Freeman, MRC Laboratory of Molecular Biology, Cambridge, UK); UAS-PKB, UASPDK1, EP837, and GMR $>W^{+}>$Gal4 (Rintelen et al. 2001); UAS-PTEN (Huang et al. 1999); UAS-Dp110 ${ }^{D N}$ (Leevers et al. 1996); Act5CGal4, Lsp2Gal4, ZCL0611 (Scylla fly trap) and $D f(3 L)$ vin4 (all from the Bloomington Drosophila Stock Center); EP1035 (from the Szeged Drosophila Stock Center); eyflp; FRT80 $\mathrm{w}^{+}$cl3L/TM6B (Newsome et al. 2000); $a k t^{3}$ (Stocker et al.
2002); $S 6 K^{1-1} / T M 6 B$ and $S 6 K^{07084} / T M 6 B$ (Montagne et al. 1999); PTEN $^{2 L 100} / \mathrm{CyO}, \mathrm{y}^{+}$, and $P T E N^{2 L 117} / \mathrm{CyO}, \mathrm{y}^{+}$(Oldham et al. 2000, 2002); PTEN ${ }^{d i 189} / C y O, y^{+}$(Gao et al. 2000); Tsc1 ${ }^{\text {Q87X }}$ / $T M 6 B, y^{+}$(Tapon et al. 2001); Tsc1 ${ }^{2 G 3}$ (H. Stocker, unpubl.); $T s c 2^{56} / T M 6 B, y^{+}$, and Tsc2 ${ }^{192} / T M 6 B, y^{+}$(Ito and Rubin 1999); UAS-tgo, UAS-trh, and UAS-sim (gifts of B. Shilo, Department of Molecular Genetics, Weizmann Institute of Science, Rehovot, Israel); UAS-sima ${ }^{\Delta 692-863}$ (Lavista-Llanos et al. 2002); daGal4/CyO (A. Wodarz, unpubl.); Thor $^{1}$ (Bernal and Kimbrell 2000).

All crosses were performed at $25^{\circ} \mathrm{C}$ if not stated otherwise.

\section{Phenotypic analyses}

Freshly eclosed adult flies were collected, separated according to sex, and placed for $24 \mathrm{~h}$ on normal fly food before weighing. Weighing was performed using a Mettler Toledo MX5 microbalance.

scylla-overexpressing wings were mounted in Euparal Mounting solution (TAAB Laboratories). Wing area was determined using Photoshop and NIH Image 1.61 to count pixels. Relative cell number and cell size was determined by extrapolating the counted hairs in a defined area $(0.1 \mathrm{~mm})^{2}$ on the dorsal side of the wing proximal to the posterior cross-vein and posterior to vein five.

Adult flies used for scanning electron microscopy were stored in $70 \%$ acetone before they were critical-point dried and coated with gold to be examined under the scanning microscope.

Adult fly heads were cut in half using a razor blade and shortly stored in Ringers on ice. Eyes were then fixed as described in Basler et al. (1991).

Heat-shock-induced Gal4 overexpression clones (y w hsflp; $G M R>W^{+}>$Gal4, where > corresponds to FRT sites) were induced $24-48 \mathrm{~h}$ after egg laying (AEL) by a 1 -h heat shock at $37^{\circ} \mathrm{C}$. The heat shock induces FLP/FRT-mediated mitotic recombination leading to the excision of the $\mathrm{w}^{+}$marker. scylla charybdis double-mutant clones were induced $24-48 \mathrm{~h}$ AEL by a $30-\mathrm{min}$ heat shock at $38^{\circ} \mathrm{C}$.

\section{Starvation experiments and lipid analysis}

Freshly eclosed flies were separated according to sex, left on normal food for $2 \mathrm{~d}$, and subsequently transferred to empty plastic vials sealed with a water-soaked foam stopper. Dead flies were counted every $4 / 8 \mathrm{~h}$. Determination of lipid and glycogen levels was done essentially as previously described (Bohni et al. 1999).

\section{Hypoxia treatment}

Larvae were exposed to the indicated $\mathrm{O}_{2}$ concentration at room temperature or at $25^{\circ} \mathrm{C}$ in a closed chamber connected to a gas-mixing pump (Digamix gas mixing pump, type M302 a-F, H Wösthoff e.H.G) that mixes air and $\mathrm{N}_{2}$, or to a ventilation pump (VENT2 pump, EMKA Technologies) that pushes a nitrogen/air mixture into the chamber. Dissection and fixation of larval tissues for mRNA in situ hybridizations and immunostainings were carried out immediately after hypoxia exposure. Scylla protein trap-larvae were dissected in Ringers, and larval tissue was fixed in $4 \%$ paraformaldehyde/PBS for $1 \mathrm{~h}$ by gentle agitation at room temperature. After a subsequent washing step, nuclei were stained by incubation for $10 \mathrm{~min}$ in DAPI $/ 0.5 \mu \mathrm{g} /$ $\mathrm{mL} / \mathrm{PBS}$ followed by three washing steps with PBS. Fluorescence images were recorded using a Zeiss Axiophot microscope.

mRNA in situ hybridizations were done essentially as described (Lehmann and Tautz 1994; O'Neill and Bier 1994). In vitro transcription was done using the DIG RNA labeling kit (Roche). DNA fragments corresponding to parts of the scylla 
and charybdis full-length mRNAs were PCR-amplified and subcloned into pCRII-TOPO vector. For the in vitro transcription, SP6 and T7 polymerases were used to produce sense and antisense RNAs.

\section{PKB-/S6K in vitro activity assays and Western blotting}

PKB assay: For each sample, 50 heads of 2-3-d-old female flies were removed with a forceps and collected on a cooled aluminum block placed on dry ice before the heads were transferred to Eppendorf tubes and flash-frozen in liquid nitrogen. Heads were squashed in $400 \mu \mathrm{L}$ of extraction buffer (Stocker et al. 2003) using a plastic pestle and subsequently treated as described previously (Radimerski et al. 2002b). One-hundred micrograms of total protein was used for the PKB assay.

For the S6K assay, second instar larvae were collected by floatation in $30 \%$ glycerol. Following a brief wash in water, batches of 20-30 larvae were transferred to 1.5-mL Eppendorf tubes and flash-frozen in liquid nitrogen. The S6K assay was done essentially as described (Oldham et al. 2000). Either 25 or $40 \mu \mathrm{g}$ of total protein was used for the S6K assay with H2B (Histone type VII-S, Sigma: H4255) as a substrate. Protein concentrations were determined using the $R C D C$ Protein Assay (Bio-Rad).

${ }^{32} \mathrm{P}$ incorporation into Crosstide or $\mathrm{H} 2 \mathrm{~B}$ was quantified and background-corrected using a PhosphorImager and image-quant software (Molecular Dynamics).

Western blotting: The following antibodies and dilutions were used: S6K D-20 antibody (Montagne et al. 1999) at 1:200 dilution, PKB antibody (Andjelkovic et al. 1995) at 1:1000 and mouse anti- $\alpha$-tubulin (Sigma) at 1:2000. HRP-conjugated secondary antibodies (Dako A/S, Glostrup) were diluted 1:2000. Since the same PKB antibody used in immunoprecipitation was also used in Western blotting, HRP-conjugated protein-A (ICN Biomedicals) at 1:5000 was used instead of secondary antibody. Signals were detected using ECL Western blotting detection reagents (Amersham Biosciences).

\section{Acknowledgments}

We are greatly indebted to Thomas Radimerski for his support and the introduction into the PKB- and S6K activity assays and critical reading of the manuscript, George Thomas for the dS6K antibodies and diverse reagents, and Brian Hemmings for the $\mathrm{dPKB}$ antibody and the PKB substrate Crosstide. We appreciate the support of Jorge Soliz and Max Gassmann for letting us use the hypoxia chamber. We thank Kathrin Doepfner for the help in generating the char ${ }^{180}$ mutant; Christof Hugentobler for excellent technical support; Pablo Wappner, Benny Shilo, and Stephen T. Crews for fly stocks; Matthias Knirr and Christoph M. Schuster for fly stocks and sharing results prior to publication; Christian Frei and Hugo Stocker for critical reading of the manuscript and insightful comments; and the entire Hafen lab for discussions.

\section{References}

Andjelkovic, M., Jones, P.F., Grossniklaus, U., Cron, P., Schier, A.F., Dick, M., Bilbe, G., and Hemmings, B.A. 1995. Developmental regulation of expression and activity of multiple forms of the Drosophila RAC protein kinase. J. Biol. Chem. 270: 4066-4075.

Arsham, A.M., Howell, J.J., and Simon, M.C. 2003. A novel hypoxia-inducible factor-independent hypoxic response regulating mammalian target of rapamycin and its targets. $J$. Biol. Chem. 278: 29655-29660.
Azevedo, R.B., French, V., and Partridge, L. 2002. Temperature modulates epidermal cell size in Drosophila melanogaster. J. Insect Physiol. 48: 231-237.

Basler, K., Christen, B., and Hafen, E. 1991. Ligand-independent activation of the sevenless receptor tyrosine kinase changes the fate of cells in the developing Drosophila eye. Cell 64: 1069-1081.

Bernal, A. and Kimbrell, D.A. 2000. Drosophila Thor participates in host immune defense and connects a translational regulator with innate immunity. Proc. Natl. Acad. Sci. 97: 6019-6024.

Bohni, R., Riesgo-Escovar, J., Oldham, S., Brogiolo, W., Stocker, H., Andruss, B.F., Beckingham, K., and Hafen, E. 1999. Autonomous control of cell and organ size by CHICO, a Drosophila homolog of vertebrate IRS1-4. Cell 97: 865-875.

Brand, A.H. and Perrimon, N. 1993. Targeted gene expression as a means of altering cell fates and generating dominant phenotypes. Development 118: 401-415.

Brogiolo, W., Stocker, H., Ikeya, T., Rintelen, F., Fernandez, R., and Hafen, E. 2001. An evolutionarily conserved function of the Drosophila insulin receptor and insulin-like peptides in growth control. Curr. Biol. 11: 213-221.

Brugarolas, J.B., Vazquez, F., Reddy, A., Sellers, W.R., and Kaelin Jr., W.G. 2003. TSC2 regulates VEGF through mTOR-dependent and -independent pathways. Cancer Cell 4: 147-158.

Brugarolas, J., Lei, K., Hurley, R.L., Manning, B.D., Reiling, J.H., Hafen, E., Witters, L.A., Ellisen, L.W., and Kaelin Jr., W.G. 2004. Regulation of mTOR function in response to hypoxia by REDD1 and the TSC1/TSC2 tumor suppressor complex. Genes \& Dev. (this issue).

Bruick, R.K. 2003. Oxygen sensing in the hypoxic response pathway: Regulation of the hypoxia-inducible transcription factor. Genes \& Dev. 17: 2614-2623.

Carling, D. 2004. The AMP-activated protein kinase cascade-A unifying system for energy control. Trends Biochem. Sci. 29: 18-24.

Cho, K.S., Lee, J.H., Kim, S., Kim, D., Koh, H., Lee, J., Kim, C., Kim, J., and Chung, J. 2001. Drosophila phosphoinositidedependent kinase-1 regulates apoptosis and growth via the phosphoinositide 3-kinase-dependent signaling pathway. Proc. Natl. Acad. Sci. 98: 6144-6149.

Ellisen, L.W., Ramsayer, K.D., Johannessen, C.M., Yang, A., Beppu, H., Minda, K., Oliner, J.D., McKeon, F., and Haber, D.A. 2002. REDD1, a developmentally regulated transcriptional target of p63 and p53, links p63 to regulation of reactive oxygen species. Mol. Cell 10: 995-1005.

Frazier, M.R., Woods, H.A., and Harrison, J.F. 2001. Interactive effects of rearing temperature and oxygen on the development of Drosophila melanogaster. Physiol. Biochem. Zool. 74: 641-650.

Frei, C. and Edgar, B.A. 2004. Drosophila cyclin D/Cdk4 requires Hif-1 prolyl hydroxylase to drive cell growth. Dev. Cell 6: 241-251.

Gao, X. and Pan, D. 2001. TSC1 and TSC2 tumor suppressors antagonize insulin signaling in cell growth. Genes \& Dev. 15: $1383-1392$.

Gao, X., Neufeld, T.P., and Pan, D. 2000. Drosophila PTEN regulates cell growth and proliferation through PI3K-dependent and -independent pathways. Dev. Biol. 221: 404-418.

Gao, X., Zhang, Y., Arrazola, P., Hino, O., Kobayashi, T., Yeung, R.S., Ru, B., and Pan, D. 2002. Tsc tumour suppressor proteins antagonize amino-acid-TOR signalling. Nat. Cell Biol. 4: 699-704.

Garami, A., Zwartkruis, F.J., Nobukuni, T., Joaquin, M., Roccio, M., Stocker, H., Kozma, S.C., Hafen, E., Bos, J.L., and Thomas, G. 2003. Insulin activation of Rheb, a mediator of 
mTOR/S6K/4E-BP signaling, is inhibited by TSC1 and 2 . Mol. Cell 11: 1457-1466.

Garofalo, R.S. 2002. Genetic analysis of insulin signaling in Drosophila. Trends Endocrinol. Metab. 13: 156-162.

Gingras, A.C., Raught, B., and Sonenberg, N. 2004. mTOR signaling to translation. Curr. Top. Microbiol. Immunol. 279: 169-197.

Goberdhan, D.C., Paricio, N., Goodman, E.C., Mlodzik, M., and Wilson, C. 1999. Drosophila tumor suppressor PTEN controls cell size and number by antagonizing the Chico/PI3kinase signaling pathway. Genes \& Dev. 13: 3244-3258.

Hay, N. and Sonenberg, N. 2004. Upstream and downstream of mTOR. Genes \& Dev. 18: 1926-1945.

Huang, H., Potter, C.J., Tao, W., Li, D.M., Brogiolo, W., Hafen, E., Sun, H., and $\mathrm{Xu}, \mathrm{T}$. 1999. PTEN affects cell size, cell proliferation and apoptosis during Drosophila eye development. Development 126: 5365-5372.

Ikeya, T., Galic, M., Belawat, P., Nairz, K., and Hafen, E. 2002. Nutrient-dependent expression of insulin-like peptides from neuroendocrine cells in the CNS contributes to growth regulation in Drosophila. Curr. Biol. 12: 1293-1300.

Inoki, K., Li, Y., Zhu, T., Wu, J., and Guan, K.L. 2002. TSC2 is phosphorylated and inhibited by Akt and suppresses mTOR signalling. Nat. Cell Biol. 4: 648-657.

Inoki, K., Li, Y., Xu, T., and Guan, K.L. 2003a. Rheb GTPase is a direct target of TSC2 GAP activity and regulates mTOR signaling. Genes \& Dev. 17: 1829-1834.

Inoki, K., Zhu, T., and Guan, K.L. 2003b. TSC2 mediates cellular energy response to control cell growth and survival. Cell 115: 577-590.

Ito, N. and Rubin, G.M. 1999. gigas, a Drosophila homolog of tuberous sclerosis gene product-2, regulates the cell cycle. Cell 96: 529-539.

Jacinto, E. and Hall, M.N. 2003. Tor signalling in bugs, brain and brawn. Nat. Rev. Mol. Cell. Biol. 4: 117-126.

Junger, M.A., Rintelen, F., Stocker, H., Wasserman, J.D., Vegh, M., Radimerski, T., Greenberg, M.E., and Hafen, E. 2003. The Drosophila Forkhead transcription factor FOXO mediates the reduction in cell number associated with reduced insulin signaling. J. Biol. 2: 7.

Kimura, N., Tokunaga, C., Dalal, S., Richardson, C., Yoshino, K., Hara, K., Kemp, B.E., Witters, L.A., Mimura, O., and Yonezawa, K. 2003. A possible linkage between AMP-activated protein kinase (AMPK) and mammalian target of rapamycin (mTOR) signalling pathway. Genes Cells 8: 65-79.

Lavista-Llanos, S., Centanin, L., Irisarri, M., Russo, D.M., Gleadle, J.M., Bocca, S.N., Muzzopappa, M., Ratcliffe, P.J., and Wappner, P. 2002. Control of the hypoxic response in Drosophila melanogaster by the basic helix-loop-helix PAS protein similar. Mol. Cell. Biol. 22: 6842-6853.

Leevers, S.J., Weinkove, D., MacDougall, L.K., Hafen, E., and Waterfield, M.D. 1996. The Drosophila phosphoinositide 3-kinase Dp110 promotes cell growth. EMBO J. 15: 65846594.

Lehmann, R. and Tautz, D. 1994. In situ hybridization to RNA. Methods Cell. Biol. 44: 575-598.

Majumder, P.K., Febbo, P.G., Bikoff, R., Berger, R., Xue, Q., McMahon, L.M., Manola, J., Brugarolas, J., McDonnell, T.J., Golub, T.R., et al. 2004. mTOR inhibition reverses Akt-dependent prostate intraepithelial neoplasia through regulation of apoptotic and HIF-1-dependent pathways. Nat. Med. 10: $594-601$.

Manning, B.D., Tee, A.R., Logsdon, M.N., Blenis, J., and Cantley, L.C. 2002. Identification of the tuberous sclerosis complex-2 tumor suppressor gene product tuberin as a target of the phosphoinositide 3-kinase/akt pathway. Mol. Cell 10: 151-162.
Montagne, J., Stewart, M.J., Stocker, H., Hafen, E., Kozma, S.C., and Thomas, G. 1999. Drosophila S6 kinase: A regulator of cell size. Science 285: 2126-2129.

Morin, X., Daneman, R., Zavortink, M., and Chia, W. 2001. A protein trap strategy to detect GFP-tagged proteins expressed from their endogenous loci in Drosophila. Proc. Nat1. Acad. Sci. 98: 15050-15055.

Neshat, M.S., Mellinghoff, I.K., Tran, C., Stiles, B., Thomas, G., Petersen, R., Frost, P., Gibbons, J.J., Wu, H., and Sawyers, C.L. 2001. Enhanced sensitivity of PTEN-deficient tumors to inhibition of FRAP/mTOR. Proc. Natl. Acad. Sci. 98: 10314-10319.

Newsome, T.P., Asling, B., and Dickson, B.J. 2000. Analysis of Drosophila photoreceptor axon guidance in eye-specific mosaics. Development 127: 851-860.

Oldham, S., Montagne, J., Radimerski, T., Thomas, G., and Hafen, E. 2000. Genetic and biochemical characterization of dTOR, the Drosophila homolog of the target of rapamycin. Genes \& Dev. 14: 2689-2694.

Oldham, S., Stocker, H., Laffargue, M., Wittwer, F., Wymann, M., and Hafen, E. 2002. The Drosophila insulin/IGF receptor controls growth and size by modulating PtdInsP(3) levels. Development 129: 4103-4109.

O'Neill J.W. and Bier, E. 1994. Double-label in situ hybridization using biotin and digoxigenin-tagged RNA probes. Biotechniques 17: 870, 874-875.

Palos, L.A. and Blasko, G. 1979. Effect of hypoxia on the development of Drosophila melanogaster (Meigen). Aviat. Space Environ. Med. 50: 411-412.

Pan, D., Dong, J., Zhang, Y., and Gao, X. 2004. Tuberous sclerosis complex: From Drosophila to human disease. Trends Cell Biol. 14: 78-85.

Pende, M., Um, S.H., Mieulet, V., Sticker, M., Goss, V.L., Mestan, J., Mueller, M., Fumagalli, S., Kozma, S.C., and Thomas, G. 2004. S6K $1^{-1-} / \mathrm{S} 6 \mathrm{~K} 2^{-1-}$ mice exhibit perinatal lethality and rapamycin-sensitive 5 '-terminal oligopyrimidine mRNA translation and reveal a mitogen-activated protein kinase-dependent S6 kinase pathway. Mol. Cell. Biol. 24: 3112-3124.

Podsypanina, K., Lee, R.T., Politis, C., Hennessy, I., Crane, A., Puc, J., Neshat, M., Wang, H., Yang, L., Gibbons, J., et al. 2001. An inhibitor of mTOR reduces neoplasia and normalizes p70/S6 kinase activity in Pten ${ }^{+/-}$mice. Proc. Natl. Acad. Sci. 98: 10320-10325.

Potter, C.J., Huang, H., and Xu, T. 2001. Drosophila Tsc1 functions with Tsc2 to antagonize insulin signaling in regulating cell growth, cell proliferation, and organ size. Cell 105: 357-368.

Radimerski, T., Montagne, J., Hemmings-Mieszczak, M., and Thomas, G. 2002a. Lethality of Drosophila lacking TSC tumor suppressor function rescued by reducing dS6K signaling. Genes \& Dev. 16: 2627-2632.

Radimerski, T., Montagne, J., Rintelen, F., Stocker, H., van der Kaay, J., Downes, C.P., Hafen, E., and Thomas, G. 2002b. dS6K-regulated cell growth is $\mathrm{dPKB} / \mathrm{dPI} / 3) \mathrm{K}$-independent, but requires dPDK1. Nat. Cell. Biol. 4: 251-255.

Rintelen, F., Stocker, H., Thomas, G., and Hafen, E. 2001. PDK1 regulates growth through Akt and S6K in Drosophila. Proc. Natl. Acad. Sci. 98: 15020-15025.

Rorth, P. 1996. A modular misexpression screen in Drosophila detecting tissue-specific phenotypes. Proc. Natl. Acad. Sci. 93: $12418-12422$.

Safran, M. and Kaelin Jr., W.G. 2003. HIF hydroxylation and the mammalian oxygen-sensing pathway. J. Clin. Invest. 111: 779-783.

Saucedo, L.J., Gao, X., Chiarelli, D.A., Li, L., Pan, D., and Edgar, B.A. 2003. Rheb promotes cell growth as a component of the insulin/TOR signalling network. Nat. Cell Biol. 5: 566-571. 
Shi, Y., Gera, J., Hu, L., Hsu, J.H., Bookstein, R., Li, W., and Lichtenstein, A. 2002. Enhanced sensitivity of multiple myeloma cells containing PTEN mutations to CCI-779. Cancer Res. 62: 5027-5034.

Shoshani, T., Faerman, A., Mett, I., Zelin, E., Tenne, T., Gorodin, S., Moshel, Y., Elbaz, S., Budanov, A., Chajut, A., et al. 2002. Identification of a novel hypoxia-inducible factor 1-responsive gene, RTP801, involved in apoptosis. Mol. Cell. Biol. 22: 2283-2293.

Stocker, H., Andjelkovic, M., Oldham, S., Laffargue, M., Wymann, M.P., Hemmings, B.A., and Hafen, E. 2002. Living with lethal PIP3 levels: Viability of flies lacking PTEN restored by a $\mathrm{PH}$ domain mutation in Akt/PKB. Science 295: 2088-2091.

Stocker, H., Radimerski, T., Schindelholz, B., Wittwer, F., Belawat, P., Daram, P., Breuer, S., Thomas, G., and Hafen, E. 2003. Rheb is an essential regulator of S6K in controlling cell growth in Drosophila. Nat. Cell Biol. 5: 559-565.

Stolovich, M., Tang, H., Hornstein, E., Levy, G., Cohen, R., Bae, S.S., Birnbaum, M.J., and Meyuhas, O. 2002. Transduction of growth or mitogenic signals into translational activation of TOP mRNAs is fully reliant on the phosphatidylinositol 3-kinase-mediated pathway but requires neither S6K1 nor rpS6 phosphorylation. Mol. Cell. Biol. 22: 8101-8113.

Sulis, M.L. and Parsons, R. 2003. PTEN: From pathology to biology. Trends Cell Biol. 13: 478-483.

Tang, H., Hornstein, E., Stolovich, M., Levy, G., Livingstone, M., Templeton, D., Avruch, J., and Meyuhas, O. 2001. Amino acid-induced translation of TOP mRNAs is fully dependent on phosphatidylinositol 3-kinase-mediated signaling, is partially inhibited by rapamycin, and is independent of S6K1 and rpS6 phosphorylation. Mol. Cell. Biol. 21: 8671-8683.

Tapon, N., Ito, N., Dickson, B.J., Treisman, J.E., and Hariharan, I.K. 2001. The Drosophila tuberous sclerosis complex gene homologs restrict cell growth and cell proliferation. Cell 105: 345-355.

Tee, A.R., Manning, B.D., Roux, P.P., Cantley, L.C., and Blenis, J. 2003. Tuberous sclerosis complex gene products, Tuberin and Hamartin, control mTOR signaling by acting as a GTPase-activating protein complex toward Rheb. Curr. Biol. 13: $1259-1268$.

Wang, Z., Malone, M.H., Thomenius, M.J., Zhong, F., Xu, F., and Distelhorst, C.W. 2003. Dexamethasone-induced gene 2 (dig2) is a novel pro-survival stress gene induced rapidly by diverse apoptotic signals. J. Biol. Chem. 278: 27053-27058.

Zhang, H., Stallock, J.P., Ng, J.C., Reinhard, C., and Neufeld, T.P. 2000. Regulation of cellular growth by the Drosophila target of rapamycin dTOR. Genes \& Dev. 14: 2712-2724.

Zhang, Y., Gao, X., Saucedo, L.J., Ru, B., Edgar, B.A., and Pan, D. 2003. Rheb is a direct target of the tuberous sclerosis tumour suppressor proteins. Nat. Cell Biol. 5: 578-581.

Zinke, I., Schutz, C.S., Katzenberger, J.D., Bauer, M., and Pankratz, M.J. 2002. Nutrient control of gene expression in Drosophila: Microarray analysis of starvation and sugar-dependent response. EMBO J. 21: 6162-6173. 


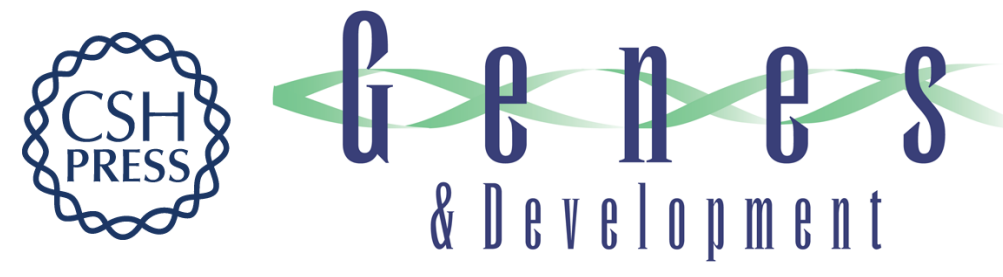

\section{The hypoxia-induced paralogs Scylla and Charybdis inhibit growth by down-regulating S6K activity upstream of TSC in Drosophila}

Jan $\mathrm{H}$. Reiling and Ernst Hafen

Genes Dev. 2004, 18:

Access the most recent version at doi:10.1101/gad.322704

Supplemental http://genesdev.cshlp.org/content/suppl/2004/11/16/gad.322704.DC1
Material

References This article cites 67 articles, 31 of which can be accessed free at:

http://genesdev.cshlp.org/content/18/23/2879.full.html\#ref-list-1

License

Email Alerting Receive free email alerts when new articles cite this article - sign up in the box at the top

Service right corner of the article or click here.

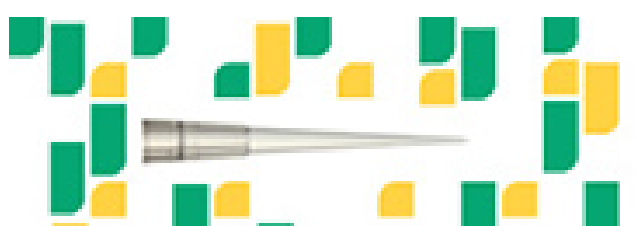

Focused on your science. 